\title{
Trends of stillbirth among reproductive-age women in Ethiopia based on Ethiopian demographic and health surveys: a multivariate decomposition analysis
}

\author{
Getayeneh Antehunegn Tesema*, Lemma Derseh Gezie and Solomon Gedlu Nigatu
}

\begin{abstract}
Background: Despite the effort to reduce stillbirth, Ethiopia remains one of the countries with the highest rate in the world. Therefore, this study aimed to analyze the trends of stillbirth among births from reproductive age women over time based on Ethiopian Demographic and Health Surveys (EDHSS).

Methods: Secondary data analysis was conducted based on the Ethiopian Demographic Health Surveys (EDHSs) conducted in 2005, 2011 and 2016. A total weighted sample of 12,037, 10,588, and 11,375 in 2005, 2011 and 2016 respectively were included for analysis. Trend and Logistic based decomposition analysis technique was used for analyzing the trends of stillbirth over time and factors contributing to the change in stillbirth rate. STATA 14 was employed for data management and analyses. All analyses presented in this paper were weighted for the sampling probabilities and non-response. Complex sampling procedures were also considered during testing of statistical significance.

Results: Among women of reproductive age, the stillbirth rate declined from 13.3/1000 births in 2005 to 9.2 per 1000 births in 2016 with the annual rate of reduction of $3.1 \%$. The study found that the stillbirth rate has been declined over time concerning the place of residence, region, antenatal care, education and place of delivery. The decomposition analysis indicated that about $82.3 \%$ of the overall change stillbirth rate was due to the difference in women's composition. Particularly, an increase in women's urban place of residence, health facility delivery, and cesarean delivery were significant predictors for the decline in stillbirth rate over the surveys.

Conclusions: The stillbirth rate has been declined over time. More than 3/4th of the decrease in stillbirth rate was due to the difference in characteristics of women over the surveys. The increase in women's urban place of residence, an increase in cesarean delivery and health facility delivery significantly contributed to the decrease in stillbirth rate over time. Public health interventions targeting rural resident women, strengthening emergency obstetric services and health facility delivery would help to maintain the decreasing trend of stillbirth rate in Ethiopia.
\end{abstract}

Keywords: Ethiopia, Multivariate decomposition analysis, Trends, Stillbirth

* Correspondence: getayenehantehunegn@gmail.com

Department of Epidemiology and Biostatistics, Institute of Public Health College of Medicine and Health Sciences, University of Gondar, Gondar, Ethiopia

C C The Author(s). 2020 Open Access This article is licensed under a Creative Commons Attribution 4.0 International License, which permits use, sharing, adaptation, distribution and reproduction in any medium or format, as long as you give appropriate credit to the original author(s) and the source, provide a link to the Creative Commons licence, and indicate if changes were made. The images or other third party material in this article are included in the article's Creative Commons licence, unless indicated otherwise in a credit line to the material. If material is not included in the article's Creative Commons licence and your intended use is not permitted by statutory regulation or exceeds the permitted use, you will need to obtain permission directly from the copyright holder. To view a copy of this licence, visit http://creativecommons.org/licenses/by/4.0/. The Creative Commons Public Domain Dedication waiver (http://creativecommons.org/publicdomain/zero/1.0/) applies to the data made available in this article, unless otherwise stated in a credit line to the data. 


\section{Background}

For international comparisons, the World Health Organization (WHO) defines stillbirth as a baby born with no sign of life at or after 28 weeks of gestation or birth weight of $1000 \mathrm{~g}$ or more or body length of $35 \mathrm{~cm}$ or more [1]. Globally in 2015, an estimated 2.6 million third trimester stillbirths, of these more than $98 \%$ occurred in low and middle-income countries and over three-quarters of these occurring in Sub-Saharan Africa (SSA) and South Asia [2]. India, Pakistan, Nigeria, China, Bangladesh, the Democratic Republic of the Congo, Ethiopia, Indonesia, Tanzania, and Afghanistan are the only 10 countries that carry the burden of over $65 \%$ of total stillbirths in the world and Ethiopia has been ranked in the seventh position [2, 3].

Stillbirth is twice as common as neonatal mortality [4] and It has reduced more slowly than maternal mortality or mortality in children younger than 5 years, which remain invisible in global policies [2] with an annual Average Rate of Reduction (ARR) of $2.0 \%$ in comparison to ARR of $3.0 \%$ for maternal death or $3.1 \%$ for neonatal death [5]. It is the commonest adverse pregnancy outcome that is less accounted for and gets relatively lower attention at both policy and implementation levels [6]. For instance, stillbirths are not accounted for in the Global Burden of Disease and the Millennium Development Goals (MDGs). Even the recently Established Sustainable Development Goals (SDGs) and targets that have been declared in 2015 did not have any focused commitment to reduce stillbirth [7].

Though Ethiopia has free obstetric services (including basic and emergency obstetric services) and prenatal care, the local health system lacks adequate qualified staff, functional equipment, and ambulance for emergency referral especially for rural residents and communities poor attitude towards maternal health service utilization makes stillbirth to not reduce as expected [8]. According to the systematic review of studies done on 16 hospital-based and few community-based studies in Ethiopia published between 1977 and 2012 the rate of stillbirth was declined from 34 to 28 per 1000 live births [9].

Stillbirth remains a public health problem, especially in developing countries where rates are 10-fold higher than in developed countries. The United Nations Every New Born Action Plan (ENAP) has set a target of 12 stillbirths per 1000 births by 2030 and 10 stillbirths per 1000 births by 2035 [10, 11]. Ninety-two mainly high-income countries have already met this target, although with marked disparities. At least 67 countries, particularly in Africa and conflict-affected areas will have to double current progress [12, 13]. It is the main indicator of the quality of the health services that are provided during pregnancy and childbirth [14].
The long-lasting impact of stillbirth remains a large burden for parents, families, policymakers and public health practitioners [12]. Evidence has shown that stillbirth is associated with physical, social and psychological morbidity, and remains a significant source of cost for the affected family and community [15]. Moreover, the complex socio-cultural consequences including grief, stigma, blame, marginalization, and anxiety which often lasts a long period are believed to bear considerable emotional and mental health effects [16]. Despite the huge burden of stillbirth on families and global health, progress made in low-middleincome countries to reduce stillbirth is considerably slower than the decline in child mortality [6]. Experiencing stillbirth had a huge impact on affected families; they suffer from grief and anxiety which often lasts a long period.

Despite achieving remarkable results in many health indicators including reducing maternal and child mortality over the last decade, Ethiopia remains one of the countries with the highest rate in the world despite relatively improved access to maternal health service over time. Although the magnitude of stillbirth in Ethiopia was among the highest in Sub Saharan Africa, stillbirth remains invisible and neglected in health policies and programs has reduced more slowly than maternal mortality and neonatal mortality [9]. Neither the Health Management Information System (HMIS) nor Ethiopian Demographic Health Surveys (EDHS) reports the magnitude and trends of stillbirth over time [17-19].

Different studies done on determinants of stillbirth showed that rural residence, parity, educational status, mode of delivery, ANC utilization, and place of delivery, maternal nutritional status, and maternal obstetric factors were the significant predictors of experiencing stillbirth [20-23]. Previous studies utilized only one point survey data [9, 24-26]; it is difficult to observe the trend and to identify factors that have been consistent in influencing stillbirth over time. Studying the change in stillbirth using multivariate decomposition analysis to identify determinant factors associated with the change in stillbirth over time has become relevant for targeting interventions to work on factors contributing to the decrease in stillbirth and could critically inform policies and programs aimed at reducing stillbirth in Ethiopia. Therefore, this study addressed such gaps by investigating the magnitude and trends as well as determining the factors contributing to the change in the Stillbirth rate over time using a Multivariate Decomposition Analysis based on 2005, 2011 and 2016 Ethiopian Demographic and Health Surveys (EDHSs). 


\section{Method and materials \\ Data}

This study was a secondary data analysis based on 2005, 2011 and 2016 Ethiopian Demographic and Health Surveys (EDHS). The EDHS used a stratified two-stage cluster sampling technique selected in two stages using the 1994 Population and Housing Census (PHC) frame for EDHS 2005, and 2007 the Population and Housing Census (PHC) frame for EDHS 2011 and 2016 as a sampling frame. Stratification was achieved by separating each region into urban and rural areas. In total, 21 sampling strata have been created because the Addis Ababa region is entirely urban. In the first stage, 540 Enumeration Areas (EAs) (145 in the urban area) for EDHS 2005, 624 EAs (187 in the urban area) for EDHS 2011 and 645 EAs (202 in the urban area) for EDHS 2016 were selected with probability proportional to the enumeration areas size and with independent selection in each sampling stratum. At the second stage, because the time has passed since the PHC, a complete household listing operation was carried out in all selected EAs before the start of fieldwork and on average 28 households were systematically selected. The detailed sampling procedure was presented in the full EDHS report [17-19]. The source of the population was all births from reproductive-age women in Ethiopia whereas all births from reproductive-age women in the selected enumeration areas were the study population.

\section{Study variables}

\section{Outcome variables}

The EDHS asked women to report any pregnancy loss that occurred in the 5 years preceding the survey. For each pregnancy that did not end in a live birth, the duration of the pregnancy was recorded. Pregnancy losses occurring after seven completed months of gestation are defined as stillbirths. The response variable of this study is the occurrence of stillbirth among mothers of childbearing age.

The response variable for the $\mathrm{i}^{\text {th }}$ mother is represented by a random variable $Y_{i}$ with two possible values coded as 1 and 0 . So, the response variable of the $i^{\text {th }}$ mother $Y_{i}$ was measured as a dichotomous variable with possible values $Y_{i}=1$, if ith mother had experienced stillbirth and $Y_{i}=0$ if mother had a live birth.

\section{Independent variables}

Socio-demographic and economic variables (residence, region, maternal age, marital status, religion, maternal education, paternal education, wealth index, maternal occupation, maternal working Status), Pregnancy and pregnancy-related factors (Mother's height, BMI, ANC visit, Parity, Preceding birth interval, contraceptive use, Place of delivery, Birth order, Mode of delivery, wanted pregnancy, Maternal anemia), Behavioral factors (Smoking, media exposure) were included for this study.

\section{Data collection procedure}

The study was conducted based on EDHS data by accessing from the DHS program official database www. measuredhs.com after permission was granted through an online request by explaining the objective of our study. The raw data was collected from all parts of the country on childbearing aged women using a structured and pre-tested questionnaire. We used the Birth Record (BR file) data set and extracted the outcome and independent variables.

\section{Data management and analysis}

The data were weighted using sampling weight, primary sampling unit, and strata before any statistical analysis to restore the representativeness of the survey and to tell the STATA to take in to account the sampling design when calculating standard errors to get reliable statistical estimates. Cross tabulations and summary statistics were conducted to describe the study population. Descriptive and summary statistics were conducted using STATA version 14 software.

Data from EDHS 2005, 2011 and 2016 were appended together after extracting important variables for trend and decomposition analysis.

\section{Trend and decomposition analysis}

The trend was assessed using descriptive analyses stratified by selected respondent characteristics and was assessed separately for the periods 2005-2011, 20112016, and 2005-2016.

A multivariate decomposition analysis of the change in stillbirth rate was employed to answer the major factors contributing to the difference in the percentage of stillbirth over the study period. This method is used for several purposes in economics, demography, medicine and other specialties. The present analysis focused on how the stillbirth rate responds to differences in women's characteristics and how these factors shape the differences across surveys conducted at different times. The analysis was a regression analysis of the difference in the percentage of stillbirth rates between EDHS 2005 and 2016. The purpose of multivariate decomposition analysis was to identify the source of difference in the percentage of stillbirth in the last 10 years. Both the difference in composition (Endowment) of population and difference in the effect of the characteristics (Coefficient) between the surveys is important to know the factors contributing to the decrease in stillbirth rate over time. The multivariate decomposition analysis for nonlinear response models utilizes the output from a logistic regression model since it is "a binary outcome" to parcel 
out the observed difference in stillbirth rate between the surveys into components. The difference in the rate of stillbirth between the surveys can be attributed to the compositional difference in population (difference in characteristics or endowment) and the difference in the effect of explanatory variables (difference in coefficient) between the surveys.

Logit based decomposition analysis technique was used for the analysis of factors contributing to the change in stillbirth over time to identify factors contributing to the change in stillbirth rate in the last 10 years.

The changes of stillbirth over time can be attributed to the compositional difference between surveys and differences in the effects of the selected explanatory. Hence, the observed difference in stillbirth between surveys is additively decomposed into a characteristics (or endowments) component and a coefficient (or effects of characteristics) component.

For logistic regression, the Logit or log-odd of stillbirth is taken as:

$$
\begin{aligned}
& \operatorname{Logit}(\mathrm{A})-\operatorname{Logit}(\mathrm{B})=\mathrm{F}(\mathrm{XA} \beta \mathrm{A})-\mathrm{F}(\mathrm{XB} \beta \mathrm{B}) \\
& =\frac{[\mathrm{F}(\mathrm{XA} \beta \mathrm{A})-\mathrm{F}(\mathrm{XB} \beta \mathrm{A})]+[\mathrm{F}(\mathrm{XB} \beta \mathrm{A})-\mathrm{F}(\mathrm{XB} \beta \mathrm{B}]}{\mathrm{E}}
\end{aligned}
$$

The E component refers to the part of the differential owing to differences in endowments or characteristics. The $\mathrm{C}$ component refers to that part of the differential attributable to differences in coefficients or effects.

The equation can be presented as:

$$
\begin{aligned}
\operatorname{Logit}(\mathrm{A})-\operatorname{Logit}(\mathrm{B})= & {[\beta 0 \mathrm{~A}-\beta 0 \mathrm{~B}] } \\
& +\Sigma \mathrm{XijB} *[\beta \mathrm{ij} \mathrm{A}-\beta \mathrm{ijB}]] \\
& +\Sigma \beta \mathrm{ijB} *[\mathrm{Xij} \mathrm{A}-\mathrm{XijB}]
\end{aligned}
$$

- $X i j \mathrm{~B}$ is the proportion of the jth category of the ith determinant in the DHS 2005,

- $X i j \mathrm{~A}$ is the proportion of the $\mathrm{jth}$ category of the ith determinant in DHS 2016,

- $B i j B$ is the coefficient of the jth category of the ith determinant in DHS 2005,

- BijA is the coefficient of the jth category of the ith determinant in DHS 2016,

- $B O B$ is the intercept in the regression equation fitted to DHS 2005, and.

- $B O A$ is the intercept in the regression equation fitted to DHS 2016.

The recently developed multivariate decomposition for the non-linear model was used for the decomposition analysis of stillbirth using mvdcmp STATA command [27].

\section{Results}

\section{Characteristics of the study population}

About half of the respondents in all three surveys were age 20-29 years. Based on the place of residence, there was a slight increment of urban residents from $7.3 \%$ in 2005 to $10.8 \%$ in 2016. According to maternal educational status, in survey 2005 more than three quarters (79.3\%) of women were not educated, while it was decreased to 69.9 and $66.9 \%$ in EDHS 2011 and 2016 respectively (Table 1 ). Besides, the proportion of women with primary education rose from 16.6 in 2005 to $26.5 \%$ in 2011 but slightly decline to $26 \%$ in 2016 . However, only a small proportion of women had 4 and above ANC visit during pregnancy in 2005 (12.2\%), the percentage rose from 12.2 to $58.3 \%$ in 2016 and the proportion of women's with no ANC visit significantly declined from $72 \%$ in 2005 to $22.9 \%$ in 2016 (Table 1).

Across the three DHS surveys, the Proportion of respondents having home delivery was significantly declined from $94.2 \%$ in 2005 to $65.7 \%$ in 2016 . Except for maternal age, region, wealth index, marital status and parity, all other variables listed in the table showed changes in composition, when comparing the sample population in the years 2005, 2011 and 2016 (Table 1).

\section{Trends in stillbirth rate}

The trend period was divided into three phases, 20052011, 2011-2016 and 2005-2016 to see the differences in stillbirth rate over time and the potential source for the change in SBR. The rate of stillbirth over the study period (2005-2016) has been declined. The largest decline was seen in the second phase (2011-2016) with a 6.2 point change in SBR but in the first phase 20052011 there was slight rose from $13.3[11.4,15.5]$ to 15.4 $[13.2,17.9]$ per 1000 births then decline to $9.2[7.6,11.1]$ (Fig. 1). The change in the stillbirth rate over the study period (2005-2016) was significant.

\section{The trends in stillbirth rate by women's characteristics}

The trend in stillbirth rate by women who gave birth within 5 years before the survey showed variation according to their characteristics (Table 2). Major Decline in stillbirth rate was observed in some of the categories. Based on the region, the stillbirth rate was increased in the first phase at a 13.2 point increase in BenishangulGumuz but declined in the second phase at 11.8 point decrease in SBR but stillbirth rate in Amhara region was consistently high over the study period (Fig. 2). Besides, there was a decrease in SBR in women with secondary and higher education with a decline in the third phase of the study period (2005-2016) at a 12.4 point decrease in the Stillbirth rate.

Concerning having 4 and above ANC visits, there was a decline in SBR over the study period with the highest 
Table 1 Percentage distribution of characteristics of respondents in 2005, 2011 and 2016 Ethiopian Demographic and Health Surveys

\begin{tabular}{|c|c|c|c|c|}
\hline Characteristics & & $\begin{array}{l}\text { Weighted frequency } \\
\text { (\%) } 2005 \\
N=12,037\end{array}$ & $\begin{array}{l}\text { Weighted frequency } \\
(\%) 2011 \\
N=10,588\end{array}$ & $\begin{array}{l}\text { Weighted frequency } \\
(\%) 2016 \\
N=11,375\end{array}$ \\
\hline \multirow[t]{4}{*}{ Women age } & $<20$ years & $576(4.7)$ & $361(3.4)$ & $374(3.3)$ \\
\hline & 20-29 years & $5825(48.5)$ & $5429(51.2)$ & $5599(49.2)$ \\
\hline & 30-39 years & $4344(36.2)$ & $3823(36.1)$ & $4382(38.5)$ \\
\hline & 40-49 years & $1292(10.7)$ & $985(9.3)$ & $1020(9.0)$ \\
\hline \multirow[t]{2}{*}{ Residence } & Rural & $11,154(92.7)$ & $9182(86.7)$ & $10,146(89.2)$ \\
\hline & Urban & $883(7.3)$ & $1406(13.3)$ & $1229(10.8)$ \\
\hline \multirow[t]{11}{*}{ Region } & Tigray & $775(6.4)$ & $678(6.4)$ & 709 (6.2) \\
\hline & Afar & $122(1.0)$ & $114(1.1)$ & $119(1.1)$ \\
\hline & Amhara & $2826(23.5)$ & $2537(24.0)$ & $2121(18.7)$ \\
\hline & Oromia & 4666 (38.8) & $4291(40.1)$ & $4997(43.9)$ \\
\hline & Somalia & $522(4.4)$ & $296(2.8)$ & $554(4.9)$ \\
\hline & Benishangul-Gumuz & $115(0.9)$ & $131(1.2)$ & $133(1.2)$ \\
\hline & SNNPRS & $2742(22.8)$ & $2248(21.2)$ & $2402(21.1)$ \\
\hline & Gambela & $34(0.3)$ & $38(0.4)$ & $29(0.3)$ \\
\hline & Harari & $23(0.2)$ & $27(0.2)$ & $27(0.2)$ \\
\hline & Addis Ababa & $170(1.4)$ & $192(1.8)$ & $234(2.0)$ \\
\hline & Dire Dawa & $41(0.3)$ & $35(0.3)$ & $49(0.4)$ \\
\hline \multirow[t]{3}{*}{ Religion } & Orthodox & $5094(42.3)$ & $4232(40.0)$ & $3844(33.8)$ \\
\hline & Muslim & $4123(38.3)$ & 3563 (33.6) & $4696(41.3)$ \\
\hline & Others $^{a}$ & $2820(23.4)$ & $2792(26.4)$ & $2835(24.9)$ \\
\hline \multirow[t]{3}{*}{ Women education } & No education & 9541 (79.3) & 7404 (69.9) & $7606(66.9)$ \\
\hline & Primary education & 1993 (16.6) & $2801(26.5)$ & $2961(26.0)$ \\
\hline & Secondary and higher education & $503(4.1)$ & $383(3.6)$ & $7.1(808)$ \\
\hline \multirow[t]{5}{*}{ Wealth index } & Poorest & $2646(21.9)$ & $2420(22.9)$ & $2483(24.1)$ \\
\hline & Poorer & $2497(20.8)$ & $2382(22.5)$ & $2623(23.0)$ \\
\hline & Middle & $2607(21.8)$ & $2151(20.3)$ & $2318(20.4)$ \\
\hline & Richer & $2468(20.4)$ & 2018 (19.1) & $2084(18.3)$ \\
\hline & Richest & $1819(15.1)$ & $1616(15.2)$ & $1613(14.2)$ \\
\hline \multirow[t]{2}{*}{ Maternal occupation } & No occupation & $8496(70.6)$ & $5727(45.9)$ & $6352(55.8)$ \\
\hline & Had occupation & $3541(29.4)$ & $4861(54.1)$ & $5023(44.2)$ \\
\hline \multirow[t]{3}{*}{ Body Mass Index of women } & Thin & $7436(61.7)$ & $2249(21.2)$ & $2483(21.8)$ \\
\hline & Normal & 4401 (36.6) & $7668(72.4)$ & $8164(71.8)$ \\
\hline & Obesity & $200(1.7)$ & $671(6.4)$ & $728(6.4)$ \\
\hline \multirow[t]{2}{*}{ Ever use contraceptive } & Yes & $2578(21.4)$ & $4745(44.8)$ & $5238(46.0)$ \\
\hline & No & 7858 (78.6) & $5843(55.2)$ & $6137(54.0)$ \\
\hline \multirow[t]{2}{*}{ Maternal anemia } & Not anemic & $4235(72.3)$ & $8728(82.4)$ & $7590(66.7)$ \\
\hline & Anemic & $1620(27.7)$ & $1860(17.6)$ & $3785(33.3)$ \\
\hline \multirow[t]{3}{*}{ Number of ANC visit } & No visit & $4920(72.0)$ & $3391(57.7)$ & $2602(22.9)$ \\
\hline & $1-3$ visit & $1091(15.8)$ & 1313 (22.3) & 2145 (18.9) \\
\hline & 4 and above visit & 834 (12.2) & $1175(20.0)$ & $6628(58.3)$ \\
\hline \multirow[t]{2}{*}{ Mode of delivery } & caesarean section & 103 (1.6) & $136(1.5)$ & $196(1.9)$ \\
\hline & Vaginal delivery & 10, $380(98.4)$ & 9333 (98.5) & $9943(98.1)$ \\
\hline
\end{tabular}


Table 1 Percentage distribution of characteristics of respondents in 2005, 2011 and 2016 Ethiopian Demographic and Health Surveys (Continued)

\begin{tabular}{|c|c|c|c|c|}
\hline Characteristics & & $\begin{array}{l}\text { Weighted frequency } \\
\text { (\%) } 2005 \\
N=12,037\end{array}$ & $\begin{array}{l}\text { Weighted frequency } \\
(\%) 2011 \\
N=10,588\end{array}$ & $\begin{array}{l}\text { Weighted frequency } \\
\text { (\%) } 2016 \\
N=11,375\end{array}$ \\
\hline \multirow[t]{2}{*}{ Place of delivery } & Home & $9873(94.2)$ & $8539(90.2)$ & $7468(65.7)$ \\
\hline & Health facility & $611(5.8)$ & $930(9.8)$ & 3907 (34.3) \\
\hline \multirow[t]{2}{*}{ Maternal height } & Less than $150 \mathrm{~cm}$ & 755 (12.9) & $1302(12.3)$ & $1228(10.8)$ \\
\hline & $\geq 150 \mathrm{~cm}$ & $5100(87.1)$ & $9286(87.7)$ & $10,147(89.2)$ \\
\hline \multirow[t]{2}{*}{ Preceding birth interval } & $<24$ month & $2315(23.4)$ & $1876(22.2)$ & 2145 (18.9) \\
\hline & $\geq 24$ month & $7597(76.6)$ & $6582(77.8)$ & $9239(81.1)$ \\
\hline \multirow[t]{3}{*}{ Parity } & Only one birth & $1197(9.9)$ & $1115(10.5)$ & 1419 (12.5) \\
\hline & 2-4 birth & $5339(44.4)$ & $4997(47.2)$ & $5022(44.1)$ \\
\hline & $\geq 5$ & $5499(45.7)$ & $4476(42.3)$ & $4934(43.4)$ \\
\hline \multirow[t]{3}{*}{ Birth order } & $1-3$ & $5812(48.3)$ & $5415(51.2)$ & $5703(50.1)$ \\
\hline & $4-5$ & $2788(23.2)$ & $2453(23.2)$ & $2655(23.4)$ \\
\hline & $\geq 6$ & $3437(28.5)$ & $2720(25.7)$ & $3017(26.5)$ \\
\hline \multirow[t]{2}{*}{ pregnancy wanted } & Wanted & $1848(15.4)$ & $9241(89.7)$ & $7703(76.0)$ \\
\hline & Not wanted & $10,189(84.6)$ & $1065(10.3)$ & $2437(24.0)$ \\
\hline \multirow[t]{2}{*}{ Media exposure } & Exposed & $4348(36.1)$ & $6060(50.9)$ & 1355 (11.9) \\
\hline & Not exposed & $7,689(63.9)$ & $4528(49.1)$ & $10,020(88.1)$ \\
\hline
\end{tabular}

Other $^{\mathrm{a}}$ : catholic and protestant

decline during the third phase (2005-2016) with point decline in 12.5 per 1000 birth (Table 2). The rate of stillbirth was declined significantly among women who gave birth at the health facility and among women gave birth through the cesarean section with point decrease of 13.2 and 24.3 per 1000 births respectively over the entire study period. According to the place of residence, the rate of stillbirth was decreased by 13.9 per 1000 births among urban residents from 2005 to 2016 (Table 2).

\section{Decomposition analysis}

Decomposition analysis of stillbirth in Ethiopia, 2005-2016

Overall from 2005 to 2016, there has been a significant decline in the stillbirth rate in Ethiopia. The overall decomposition result showed that the decline in stillbirth over time has been explained by the differences in women's characteristics between the surveys. About $82.3 \%$ of the decrease in stillbirth was attributed to the differences in the composition of the respondent but the change due to the differences in the effect of selected explanatory variables was not significant (Table 3 ).

In the detailed decomposition analysis, the overall decrease in stillbirth between 2005 and 2016 was attributed to the differences in characteristics (endowment) of women between the surveys. The most important independent variables that provide significant contributions were the mode of delivery, place of delivery, and place of residence. The increase in the composition of women with

\section{stillbirth rate over time}

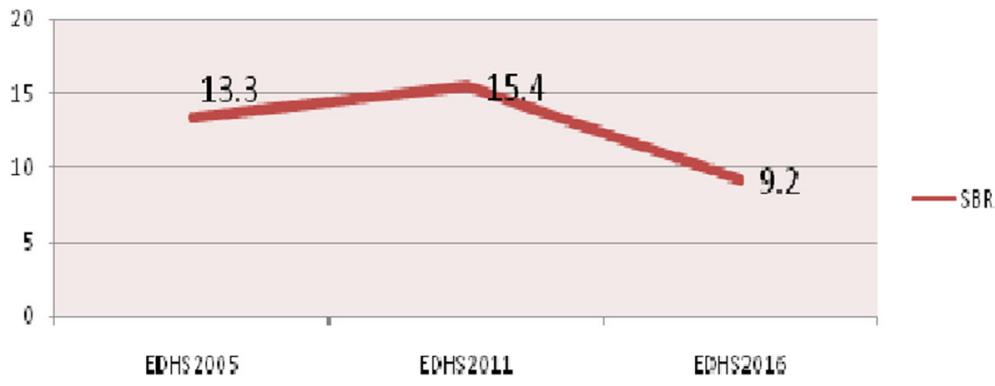

Fig. 1 The trends of stillbirth rate in Ethiopia from 2005 to 2016 
Table 2 Trends in stillbirth rate among women's who gave birth in the last five years prior to the surveys by selected characteristics 2005, 2011, and 2016 Ethiopia Demographic and Health Surveys

\begin{tabular}{|c|c|c|c|c|c|c|}
\hline \multirow[t]{2}{*}{ Characteristics } & \multirow{2}{*}{$\begin{array}{l}2005 \\
N=12037\end{array}$} & \multirow{2}{*}{$\begin{array}{l}2011 \\
N=10588\end{array}$} & \multirow{2}{*}{$\begin{array}{l}2016 \\
N=11375\end{array}$} & \multicolumn{3}{|c|}{ point difference in stillbirth rate } \\
\hline & & & & $\begin{array}{l}\text { Phase } 1 \\
2011-2005\end{array}$ & $\begin{array}{l}\text { Phase } 2 \\
2016-2011\end{array}$ & $\begin{array}{l}\text { Phase } 3 \\
\text { 2016-2005 }\end{array}$ \\
\hline \multicolumn{7}{|l|}{ Residence } \\
\hline Urban & 14.7 & 6.3 & 0.8 & -8.4 & -5.5 & -13.9 \\
\hline Rural & 13.2 & 16.8 & 10.2 & 3.6 & -6.6 & -3.0 \\
\hline \multicolumn{7}{|l|}{ Religion } \\
\hline Orthodox & 13.4 & 17.9 & 12.7 & 4.5 & -5.2 & -0.7 \\
\hline Muslim & 9.8 & 14.7 & 11.0 & 4.9 & -3.7 & 1.2 \\
\hline Other* & 15.6 & 12.6 & 1.3 & -3.0 & -11.3 & -14.3 \\
\hline \multicolumn{7}{|l|}{ Maternal age } \\
\hline$<20$ & 17.4 & 11.2 & 17.1 & -6.2 & 5.9 & -0.3 \\
\hline $20-29$ & 12.9 & 18.2 & 9.3 & 5.3 & -8.9 & -3.6 \\
\hline $30-39$ & 11.5 & 13.1 & 7.8 & 1.6 & -5.3 & -3.7 \\
\hline $40+$ & 19.4 & 10.8 & 11.4 & -8.6 & 0.6 & -8.0 \\
\hline \multicolumn{7}{|l|}{ Maternal occupation } \\
\hline Had occupation & 9.6 & 17.5 & 11.8 & 7.9 & -5.7 & 2.2 \\
\hline No occupation & 14.9 & 13.7 & 7.1 & -1.2 & -6.6 & -7.8 \\
\hline \multicolumn{7}{|l|}{ Women's education } \\
\hline No education & 14.9 & 17.4 & 10.8 & 2.5 & -6.6 & -4.1 \\
\hline Primary education & 4.4 & 11.0 & 5.9 & 6.6 & -5.1 & 1.5 \\
\hline Secondary and above & 18.8 & 10.6 & 6.4 & -8.2 & -4.2 & -12.4 \\
\hline \multicolumn{7}{|l|}{ Parity } \\
\hline 1 & 26.9 & 32.8 & 16.3 & 5.9 & -16.5 & -10.6 \\
\hline $2-4$ & 13.0 & 14.1 & 11.1 & 1.1 & -3.0 & -1.9 \\
\hline$\geq 5$ & 13.3 & 12.7 & 5.1 & -0.6 & -7.6 & -8.2 \\
\hline \multicolumn{7}{|l|}{ Birth order } \\
\hline $1-3$ & 16.3 & 18.0 & 13.2 & 1.7 & -4.8 & -3.1 \\
\hline $4-5$ & 6.9 & 14.8 & 6.6 & 7.9 & -8.2 & -0.3 \\
\hline$\geq 6$ & 13.5 & 10.9 & 3.8 & -2.6 & -7.1 & -9.7 \\
\hline \multicolumn{7}{|l|}{ Place of delivery } \\
\hline Home & 12.7 & 15.8 & 8.1 & 3.1 & -7.7 & -4.6 \\
\hline Health facility & 24.5 & 9.5 & 11.3 & -15.0 & 1.8 & -13.2 \\
\hline \multicolumn{7}{|l|}{ Mode of delivery } \\
\hline Caesarean section & 53.3 & 23.0 & 29.9 & -33.3 & 6.9 & -23.4 \\
\hline Vaginal delivery & 13.0 & 15.1 & 8.5 & 2.1 & -6.6 & -4.5 \\
\hline \multicolumn{7}{|l|}{ Number of ANC visit } \\
\hline No visit & 15.7 & 21.4 & 15.4 & 5.7 & -6.0 & -0.3 \\
\hline $1-3$ visit & 13.0 & 15.9 & 8.3 & 2.9 & -7.6 & -4.7 \\
\hline$\geq 4$ visit & 19.5 & 11.0 & 7.0 & -8.5 & -4.0 & -12.5 \\
\hline \multicolumn{7}{|l|}{ Maternal anemia } \\
\hline Yes & 8.1 & 31.9 & 12.0 & 23.8 & -19.9 & 3.9 \\
\hline No & 14.9 & 11.9 & 7.8 & -3.0 & -4.1 & -7.1 \\
\hline \multicolumn{7}{|l|}{ Wealth index } \\
\hline Poorest & 10.5 & 17.7 & 9.5 & 6.2 & -8.2 & -1.0 \\
\hline
\end{tabular}


Table 2 Trends in stillbirth rate among women's who gave birth in the last five years prior to the surveys by selected characteristics 2005, 2011, and 2016 Ethiopia Demographic and Health Surveys (Continued)

\begin{tabular}{|c|c|c|c|c|c|c|}
\hline \multirow[t]{2}{*}{ Characteristics } & \multirow{2}{*}{$\begin{array}{l}2005 \\
N=12037\end{array}$} & \multirow{2}{*}{$\begin{array}{l}2011 \\
N=10588\end{array}$} & \multirow{2}{*}{$\begin{array}{l}2016 \\
N=11375\end{array}$} & \multicolumn{3}{|c|}{ point difference in stillbirth rate } \\
\hline & & & & $\begin{array}{l}\text { Phase } 1 \\
\text { 2011-2005 }\end{array}$ & $\begin{array}{l}\text { Phase } 2 \\
2016-2011\end{array}$ & $\begin{array}{l}\text { Phase } 3 \\
\text { 2016-2005 }\end{array}$ \\
\hline Poorer & 9.7 & 15.6 & 11.5 & 5.9 & -4.1 & 1.8 \\
\hline Middle & 13.8 & 23.5 & 10.2 & 9.7 & -13.3 & -3.6 \\
\hline Richer & 19.0 & 11.6 & 6.9 & -7.4 & -4.7 & -12.1 \\
\hline Richest & 14.1 & 5.9 & 6.2 & -8.2 & 0.3 & -7.9 \\
\hline \multicolumn{7}{|l|}{ BMl } \\
\hline Thin & 12.3 & 15.0 & 10.4 & 2.7 & -4.6 & -1.9 \\
\hline Normal & 13.7 & 16.3 & 9.1 & 2.6 & -7.2 & -4.6 \\
\hline Overweight & 42.3 & 7.1 & 6.3 & -35.2 & -0.8 & -36.0 \\
\hline \multicolumn{7}{|l|}{ Maternal height } \\
\hline$<150 \mathrm{~cm}$ & 13.0 & 37.3 & 15.3 & 24.3 & -22.0 & 2.3 \\
\hline$\geq 150 \mathrm{~cm}$ & 13.0 & 12.4 & 8.4 & -0.6 & -4.0 & -4.6 \\
\hline \multicolumn{7}{|c|}{ Preceding birth interval } \\
\hline$<24$ month & 8.9 & 10.6 & 11.8 & 1.7 & 1.2 & 2.9 \\
\hline$\geq 24$ months & 12.1 & 14.1 & 8.6 & 2.0 & -5.5 & -3.5 \\
\hline \multicolumn{7}{|c|}{ Was the pregnancy wanted } \\
\hline Yes & 11.8 & 15.4 & 9.6 & 3.6 & -5.8 & -2.2 \\
\hline No & 13.6 & 12.6 & 5.0 & -1.0 & -7.6 & -8.6 \\
\hline \multicolumn{7}{|c|}{ Ever use contraceptive } \\
\hline Yes & 20.4 & 13.5 & 5.9 & -6.9 & -7.6 & -14.5 \\
\hline No & 11.4 & 17.0 & 12.0 & 5.6 & -5.0 & 0.6 \\
\hline \multicolumn{7}{|l|}{ Media exposure } \\
\hline Yes & 11.4 & 15.5 & 3.3 & 4.1 & -12.2 & -8.1 \\
\hline No & 16.7 & 15.4 & 10.0 & -1.3 & -5.4 & -6.7 \\
\hline Overall & $13.3[11.4,15.5]$ & $15.4[13.2,17.9]$ & $9.2[7.6,11.1]$ & 2.1 & -6.2 & -4.1 \\
\hline
\end{tabular}

*represents protestant, catholic and traditional religion followers

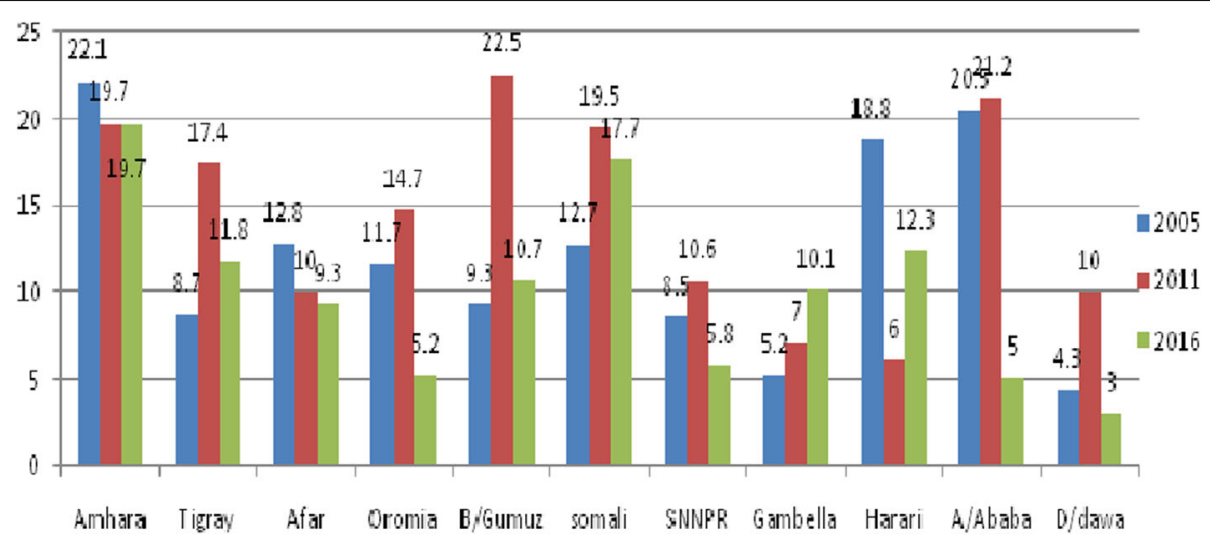

Fig. 2 The trends of stillbirth rate over time across regions in Ethiopia 2005, 2011 and 2016 
Table 3 Overall decomposition analysis of change in stillbirth in Ethiopia 2005-2016

\begin{tabular}{llll}
\hline Stillbirth & Coef. & [95\% Conf. Interval] & Pct. \\
\hline E & -.0053 & $-0.0098-0.00081$ & $82.3^{*}$ \\
C & -.00113 & -0.0080 .006 & 17.7 \\
R & -0.0064 & $-0.001-0.0017^{* *}$ & \\
\hline
\end{tabular}

"E:endowment; C:coefficient; R: residual; * $p$-value $<0.05$; ** $p$-value $<0.01$

urban residence from 2005 to 2016 was significantly contributed to the decrease in stillbirth. Also, an increase in the composition of women with health facility delivery over time (from 2005 to 2016) was significantly contributed to the decrease in stillbirth, which contributes $19.3 \%$. Similarly, an increase in the composition of women with cesarean delivery over time (from 2005 to 2016) significantly contributed to the change in stillbirth about $1.4 \%$ of the change in stillbirth (Table 4).

\section{Discussion}

Stillbirth is a major but often overlooked public health issue [28]. The incidence of stillbirth in a community is a reflection of the level of antenatal care and delivery service availability and utilization [29]. The study investigated the trends and determinants of stillbirth among reproductive-age women in Ethiopia. The study aimed to identify the major factors positively or negatively contributing to the change in stillbirth rate in the past 10 years based on data from 2005, 2011 and 2016 Ethiopian Demographic and Health Surveys.

In this study, the trend in the stillbirth rate has been significantly declined over time. The stillbirth rate declined from 13.3/1000 birth in 2005 to $9.2 / 1000$ births with an annual reduction rate of $3.1 \%$. Which is in line with a systematic review done in Ethiopia [9]. This could be attributed to the establishment of health extension workers that improve maternal and child health service delivery in the district by delivering appropriate information about the different available services to the mothers at the community and household level and health development army to facilitate access to basic maternal health service especially for rural residents [30]. Besides, in Ethiopia Antenatal Care (ANC) utilization is increased through time [31]. This could help a pregnant woman to seek early treatment for her potential pregnancyassociated complications, early screening of underlying

Table 4 Detailed decomposition analysis of change in stillbirth in Ethiopia 2005-2016

\begin{tabular}{|c|c|c|c|c|c|}
\hline \multicolumn{2}{|l|}{ Experiencing stillbirth } & \multicolumn{2}{|c|}{ Difference due to characteristics(E) } & \multicolumn{2}{|c|}{ Difference due to coefficient (C) } \\
\hline & & \multirow{2}{*}{$\begin{array}{l}\text { Coef. } \\
-0.0001^{* *}[-0.0001,-0.002]\end{array}$} & \multirow{2}{*}{$\begin{array}{l}\text { Pct. } \\
0.9\end{array}$} & \multirow{2}{*}{$\begin{array}{l}\text { Coef. } \\
0.006[-0.03,0.04]\end{array}$} & \multirow{2}{*}{$\frac{\text { Pct. }}{-94.6}$} \\
\hline Residence & Rural & & & & \\
\hline & Urban & & & & \\
\hline \multirow[t]{3}{*}{ Maternal education } & No education & & & & \\
\hline & Primary education & $-0.0007[-0.002,0.0001]$ & 10.4 & $0.0003[-0.002,0.002]$ & -5.1 \\
\hline & Secondary and higher & $-0.000003[-0.00003,0.0002]$ & 0.05 & $0.00001[-0.0003,0.0004]$ & -0.9 \\
\hline \multirow[t]{2}{*}{ Mode of delivery } & Vaginal delivery & & & & \\
\hline & Caesarean section & $0.00009^{*}[0.00002,00002]$ & -1.4 & $0.00004[-0.0002,0.0003]$ & -0.6 \\
\hline \multirow[t]{2}{*}{ Place of delivery } & Home & & & & \\
\hline & Health facility & $0.0012^{*}[0.0003,0.002]$ & -19.3 & $0.00006[-0.0004,0.0005]$ & -0.9 \\
\hline \multirow[t]{3}{*}{ Parity } & Only one birth & & & & \\
\hline & $2-4$ birth & $-0.00007[-0.0003,0.0002]$ & 1.1 & $0.0005[-0.002,0.003]$ & -7.0 \\
\hline & $\geq 5$ birth & $-0.0002[-0.0004,00001]$ & 2.8 & $-0.000525[-0.004,0.002]$ & 8.2 \\
\hline \multirow[t]{2}{*}{ use contraceptive } & Yes & & & & \\
\hline & No & $-0.0013[-0.002,0.000002]$ & 20.7 & $0.003[-0.012,0.018]$ & -45.2 \\
\hline \multirow[t]{3}{*}{ Wealth status } & Poor & & & & \\
\hline & Middle & $-0.00005[-0.0003,0.00002]$ & 0.1 & $-0.00009[-0.0009,0.0007]$ & 1.4 \\
\hline & Rich & $0.00003[-.00002,0.0002]$ & -0.4 & $-0.00064[-0.004,0003]$ & 9.9 \\
\hline \multirow[t]{3}{*}{ Number of ANC visit } & No ANC visit & & & & \\
\hline & $1-3$ visit & $-0.0003[-0.0007,0.0001]$ & 4.5 & $-0.0002[-0.001,0.0008]$ & 2.9 \\
\hline & $\geq 4$ visit & $-0.003[-0.006,0.0002]$ & 41.4 & $-0.0003[-0.002,0.001]$ & 5.1 \\
\hline total & & & 82.3 & & 17.7 \\
\hline Constant & & & & $-0.009[-0.06,0.04]$ & \\
\hline
\end{tabular}

${ }^{*} P$-value $<0.05 ;{ }^{* *} p$-value $<0.01$ 
medical conditions and may improve birth outcomes by promoting deliveries in health facilities where complications can be better managed and have access to information related to nutrition, and danger signs of pregnancy [32]. Based on this study result Ethiopia achieved the Every Newborn Action plan set by WHO, a global multi-partner movement to reduce stillbirth rates globally to 12 or less per 1000 births by 2030 [11, 33].

In the decomposition analysis, the stillbirth rate (2005-2016) has shown a remarkable decrement in Ethiopia. Hence, understanding the source of change has public health importance to uncover what are the contributing factors for the change in stillbirth as well as understanding where we are making progress in reducing stillbirth to evaluate already implemented strategies and to work on factors contributing to the change in the trend of stillbirth.

$82.3 \%$ of the decreases in stillbirth rate over the entire study period (2005-2016) was attributed to the differences in women's composition over the surveys. An increase in the composition of urban resident women over the survey showed a significant effect on the decrease in stillbirth. This finding is consistent within South Africa [34], African Great lake Regions [35], Nigeria [20], Northern Ghana [23] and Ethiopia [24]. This could be due to the increase in urbanization in Ethiopia over time [36] and increased urbanization has significant role in improving access to maternal health service especially emergency obstetric cases can be managed since they are near to the health facilities, and had relatively improved awareness towards maternal health service utilization as compared to rural residents [37].

An increase in cesarean delivery over time had a significant effect on the decline of stillbirth over time. This finding was in line with prior study in England [38], this could be the fact that cesarean delivery is done in advanced setting and the health facilities are increasing over time in Ethiopia. Therefore intrapartum stillbirth can be managed in emergency cases through the cesarean section in situations like cord prolapse, placental Previa and fetal distress and could save the baby [39].

Besides, an increased health facility delivery over the survey's had a significant effect on the decline in stillbirth. This might be due to the reason that most of the stillbirth are occurred during intrapartum period [40] due to complications arising during labor this could be managed for women who gave birth at health facility since there are skilled birth attendants, emergency care is available at health facility and access to quality obstetric care at the time of delivery can reduce preventive stillbirth this could be the possible reason.

The limitations of the study were, the EDHS data didn't measure many other important factors, for example, those related to maternal health service availability and quality, maternal medical and obstetric conditions: Variables like Diabetes mellitus, Hypertension, HIV/AIDS, heart failure, renal diseases, and maternal obstetric complications such as Antepartum hemorrhage, preeclampsia, eclampsia, premature rupture of membrane, polyhydramnios, IUGR, preconception BMI, folate supplementation before pregnancy, congenital anomalies, $\mathrm{ABO}$ incompatibility, women knowledge and attitude towards stillbirth, RH iso-immunization which are considered as the most common cause of Stillbirth were not addressed in this study because these variables were not available. While decomposition analysis is a promising tool to analyze contributions of various factors to changes in outcome, our model is constrained by the limited availability of data to explain the difference. Further research is needed including an alternative methodology to the decomposition analysis.

\section{Conclusions}

Stillbirth rates had shown a remarkable decrease over the last 10 years in Ethiopia. More than 3/4th of the overall decrease in stillbirth rate among reproductiveage women over the 10 years was due to differences in characteristics of respondents between 2005 and 2016 EDHS. Changes in the composition of reproductive age women's characteristics according to the place of residence, mode of delivery and place of residence were the major sources of the decrease in stillbirth rate over the study. Public health interventions, including strengthening health facility delivery for women to further reduce stillbirth particularly for rural residents.

\section{Abbreviations \\ ANC: Antenatal Care; ARR: Annual Rate of Reduction; BMl: Body Mass Index; Cl: Confidence Interval; CSA: Central Statistical Agency; DHS: Demographic Health Survey; EA: Enumeration Area; EDHS: Ethiopian Demographic Health Survey; PHC: Population and Housing census; SBR: Stillbirth Rate; SNNPRs: Southern Nations and Nationality People Regional state; WHO: World Health Organization}

\section{Acknowledgments \\ We would like to thank the measure DHS program for providing the data set.}

\section{Authors' contributions}

Conceptualization: Getayeneh Antehunegn Tesema. Data curation: Getayeneh Antehunegn Tesema. Funding acquisition: Getayeneh Antehunegn Tesema. Investigation: Getayeneh Antehunegn Tesema, Lemma Derseh, Solomon Gedlu. Methodology: Getayeneh Antehunegn Tesema, Lemma Derseh, Solomon Gedlu. Project administration: Getayeneh Antehunegn Tesema, Lemma Derseh, Solomon Derseh. Resources: Getayeneh Antehunegn Tesema, Lemma Derseh, Solomon Derseh. Software: Getayeneh Antehunegn Tesema, Lemma Derseh, Solomon Derseh. Supervision: Getayeneh Antehunegn Tesema, Lemma Derseh, Solomon Derseh. Validation: Getayeneh Antehunegn Tesema, Lemma Derseh, Solomon Derseh. Visualization: Getayeneh Antehunegn Tesema, Lemma Derseh, Solomon Derseh. Writing: Getayeneh Antehunegn Tesema. Writing review and editing: Getayeneh Antehunegn Tesema, Lemma Derseh, Solomon Derseh. The authors read and approved the final manuscript. 


\section{Funding}

No funding was obtained for this study.

\section{Availability of data and materials}

Data is available online and you can access it from www.measuredhs.com

\section{Ethics approval and consent to participate}

Ethical clearance was obtained from the Institutional Review Board of Institute of Public Health, CMHS, and the University of Gondar. Permission for data access was obtained from major demographic and health survey through the online request from http://www.dhsprogram.com. The data used for this study were publicly available with no personal identifier.

\section{Consent for publication}

Not applicable.

\section{Competing interests}

The authors declare that they have no competing interests.

\section{Received: 16 August 2019 Accepted: 17 March 2020} Published online: 30 March 2020

\section{References}

1. Harris ST, Zeng X, Ford L. International classification of diseases, 10th revision: it's coming, ready or not. Health Care Manag. 2011;30(3):227-35..

2. Lawn JE, Blencowe H, Waiswa P, Amouzou A, Mathers C, Hogan D, et al. Stillbirths: rates, risk factors, and acceleration towards 2030. Lancet. 2016; 387(10018):587-603.

3. Cousens S, Blencowe H, Stanton C, Chou D, Ahmed S, Steinhardt L, et al. National, regional, and worldwide estimates of stillbirth rates in 2009 with trends since 1995: a systematic analysis. Lancet. 2011;377(9774):1319-30.

4. Lawrence D, Hancock KJ, Kisely S. The gap in life expectancy from preventable physical illness in psychiatric patients in Western Australia: retrospective analysis of population based registers. BMJ. 2013;346:f2539.

5. You D, Hug L, Ejdemyr S, Idele P, Hogan D, Mathers C, et al. Global, regional, and national levels and trends in under-5 mortality between 1990 and 2015, with scenario-based projections to 2030: a systematic analysis by the UN inter-agency Group for Child Mortality Estimation. Lancet. 2015; 386(10010):2275-86

6. Stanton C, Lawn JE, Rahman H, Wilczynska-Ketende K, Hill K. Stillbirth rates: delivering estimates in 190 countries. Lancet. 2006;367(9521):1487-94.

7. Kumar S, Kumar N, Vivekadhish S. Millennium development goals (MDGS) to sustainable development goals (SDGS): addressing unfinished agenda and strengthening sustainable development and partnership. Indian J Community Med. 2016;41(1):1.

8. Pearson L, Gandhi M, Admasu K, Keyes EB. User fees and maternity services in Ethiopia. Int J Gynecol Obstet. 2011;115(3):310-5.

9. Berhan Y, Berhan A. Perinatal mortality trends in Ethiopia. Ethiop J Health Sci. 2014;24:29-40

10. de Bernis L, Kinney MV, Stones W, ten Hoope-Bender P, Vivio D, Leisher SH, et al. Stillbirths: ending preventable deaths by 2030. Lancet. 2016; 387(10019):703-16.

11. Chou D, Daelmans B, Jolivet RR, Kinney M, Say L. Ending preventable maternal and newborn mortality and stillbirths. BMJ. 2015;351:h4255.

12. Lawn JE, Blencowe H, Waiswa P, Amouzou A, Mathers C, Hogan D, et al. Stillbirths: rates, risk factors and potential for progress towards 2030. Lancet. 2016;387(10018):587-603.

13. UNICEF W. Every newborn: an action plan to end preventable deaths. Geneva: WHO; 2014

14. Admasu K, Haile-Mariam A, Bailey P. Indicators for availability, utilization, and quality of emergency obstetric care in Ethiopia, 2008. Int J Gynecol Obstet. 2011;115(1):101-5

15. Mullan Z, Horton R. Bringing stillbirths out of the shadows. Lancet. 2011; 377(9774):1291-2

16. Turton P, Evans C, Hughes P. Long-term psychosocial sequelae of stillbirth: phase II of a nested case-control cohort study. Arch Womens Ment Health. 2009;12(1):35.

17. ICF CSACEa. Ethiopia Demographic and Health Survey 2016. Addis Ababa, Ethiopia, and Rockville, Maryland: CSA and ICF; 2016.

18. International CSAEal. Ethiopia Demographic and Health Survey 2011. Addis Ababa, Ethiopia and Calverton, Maryland: CSA and ICF International; 2012.
19. macro CsAEaO. Ethiopian Demographic and Health survey 2005. Addis Ababa, Ethiopia and Calverton, Maryland: CSA and ORC macro; 2005.

20. Dahiru T, Aliyu AA. Stillbirth in Nigeria: rates and risk factors based on 2013 Nigeria DHS. Open Access Library J. 2016:3(08):1.

21. Ali AAA, Adam I. Anaemia and stillbirth in Kassala hospital, eastern Sudan. J Trop Pediatr. 2010;57(1):62-4.

22. Badshah S, Mason L, Lisboa PJ. Risk factors associated with stillbirths in public-hospitals in Peshawar, Pakistan. J Hum Soc Sci. 2011;19(2):15.

23. Badimsuguru AB, Nyarko KM, Afari EA, Sackey SO, Kubio C. Determinants of stillbirths in Northern Ghana: a case control study. Pan Afr Med J. 2016:25(Suppl 1)..

24. Berhie KA, Gebresilassie HG. Logistic regression analysis on the determinants of stillbirth in Ethiopia. Matern Health Neonatol Perinatol. 2016;2(1):10.

25. Lakew D, Tesfaye D, Mekonnen H. Determinants of stillbirth among women deliveries at Amhara region, Ethiopia. BMC Pregnancy Childbirth. 2017;17(1):375

26. Tilahun D, Assefa T. Incidence and determinants of stillbirth among women who gave birth in Jimma University specialized hospital, Ethiopia. Pan Afr Med J. 2017;28(1)

27. Powers DA, Yoshioka H, Yun M-S. mvdcmp: multivariate decomposition for nonlinear response models. Stata J. 2011;11(4):556-76.

28. Flenady V, Wojcieszek AM, Middleton P, Ellwood D, Erwich JJ, Coory M, et al. Stillbirths: recall to action in high-income countries. Lancet. 2016;387(10019): 691-702.

29. Cotzias CS, Paterson-Brown S, Fisk NM. Prospective risk of unexplained stillbirth in singleton pregnancies at term: population based analysis. BMJ. 1999;319(7205):287-8.

30. Medhanyie A, Spigt M, Kifle Y, Schaay N, Sanders D, Blanco R, et al. The role of health extension workers in improving utilization of maternal health services in rural areas in Ethiopia: a cross sectional study. BMC Health Serv Res. 2012:12(1):352.

31. Regassa N. Antenatal and postnatal care service utilization in southern Ethiopia: a population-based study. Afr Health Sci. 2011;11(3).

32. Mrisho M, Obrist B, Schellenberg JA, Haws RA, Mushi AK, Mshinda H, et al The use of antenatal and postnatal care: perspectives and experiences of women and health care providers in rural southern Tanzania. BMC Pregnancy Childbirth. 2009;9(1):10.

33. UNICEF. WHO. Every newborn: an action plan to end preventable newborn deaths. 2013.

34. Nfii FN. Levels, trends and household determinants of stillbirths and miscarriages in South Africa (2010-2014); 2017.

35. Akombi BJ, Ghimire PR, Agho KE, Renzaho AM. Stillbirth in the African Great Lakes region: a pooled analysis of demographic and health surveys. PLoS One. 2018:13(8):e0202603.

36. Tesfaunegn EA. Urban and Peri -urban development dynamics in EthiopiaSwiss Agency for Development and CooperationUrban and Periurban development dynamics in Ethiopia. Addis Ababa: Swiss Agency for Development and Cooperation; 2017.

37. Harpham T. Urbanization and mental health in developing countries: a research role for social scientists, public health professionals and social psychiatrists. Soc Sci Med. 1994;39(2):233-45.

38. Minkoff $\mathrm{H}$, Chervenak FA. Elective primary cesarean delivery. N Engl J Med. 2003:348(10):946-50.

39. Sholl JS. Abruptio placentae: clinical management in nonacute cases. Am J Obstet Gynecol. 1987;156(1):40-51.

40. Organization WH. Neonatal and perinatal mortality: country, regional and global estimates. 2006

\section{Publisher's Note}

Springer Nature remains neutral with regard to jurisdictional claims in published maps and institutional affiliations. 